\title{
ANÁLISE MORFOMÉTRICA E DO USO DA TERRA DA BACIA HIDROGRÁFICA DO CÓRREGO DA ONÇA, PRESIDENTE PRUDENTE- SP
}

\author{
Morphometric analysis and land use of the hydrographic basin of córrego da \\ Onça, Presidente Prudente- SP
}

\author{
Edmiler José Silva Degrande \\ Universidade Estadual Paulista-UNESP \\ edmiler.js@hotmail.com \\ Glauber Verner Firmino \\ Universidade Estadual Paulista-UNESP \\ glauberverner@gmail.com
}

\section{Recebido em 12/10/2020 Aceito em 06/11/2020}

RESUMO: O presente trabalho visa analisar as características morfométricas e do uso da terra na bacia hidrográfica do córrego da Onça, no município de Presidente Prudente- SP, como subsídio ao planejamento ambiental da área em questão. O estudo parte do pressuposto teórico metodológico exposto por Christofoletti (1980), sendo analisados dados referentes ás características morfométricas: linear, areal e hipsométricas da bacia e ainda de suas relações com u uso da terra Os dados base foram extraídos de imagens Shuttle Radar Topography Mission- SRTM, os quais foram processados nos softwares Arc Gis 10.3 e Google Earth, e então, calculados os valores morfométricos, já o mapeamento do uso da terra foi realizado com o uso de imagens de satélite Landsat 7 e 8 . A partir dos resultados quantitativos obtidos, a bacia hidrográfica do córrego da Onça foi classifica como de drenagem dendrítica, possuindo hierarquia de drenagem de $4^{\mathrm{a}}$ ordem. Sua classificação como retangular, de forma alongada, Ihe concede certa estabilidade quanto ao risco de cheias, considerando sua média de precipitação anual, sem eventos extremos. A baixa densidade de drenagem e o médio índice de rugosidade do relevo reforçam o caráter de estabilidade da bacia à picos de cheias, entretanto, a predominância de solos suscetíveis a erosão, além do processo de ocupação inadequada da área, demonstra a necessidade de procedimentos de uso e manejo da terra de modo sustentável. Dessa forma a metodologia aplicada e os resultados obtidos têm se mostrado importantes como ferramenta ao planejamento ambiental e consequentemente na atenuação de impactos ambientais adversos.

Palavras-chave: Morfometria; Bacia hidrográfica; Planejamento ambiental.

ABSTRACT: This work aims to analyze the morphometric characteristics and land use in the hydrographic basin of the Onça stream, in the municipality of Presidente Prudente-SP, as a subsidy to the environmental planning of the area in question. The study starts from the theoretical and methodological assumption exposed by Christofoletti (1980), analyzing data regarding the morphometric characteristics: linear, area and hypsometric of the basin and also its relations with land use. Base data were extracted from Shuttle Radar Topography Mission images - SRTM, which were processed in the software Arc Gis 10.3 and Google Earth, and then, the morphometric values were calculated, the land use mapping was performed using Landsat 7 and 8 satellite images. From the quantitative results obtained, the hydrographic basin of the Onça stream was classified as dendritic drainage, having a 4th order drainage hierarchy. Its classification as rectangular, of elongated shape, gives it some stability regarding the risk of floods, considering its average annual precipitation, without extreme events. The low drainage density and the medium roughness index of the relief reinforce the stability of the basin to flood peaks, however, the predominance of soils susceptible to erosion, in addition to the process of inadequate occupation of the area, demonstrate the need for drainage procedures sustainable land use and management. In this way, the applied methodology and the results 
ANÁLISE MORFOMÉTRICA E DO USO DA TERRA DA BACIA HIDROGRÁFICA DO CÓRREGO DA ONÇA, PRESIDENTE PRUDENTE- SP

obtained have been shown to be important as a tool for environmental planning and consequently in mitigating adverse environmental impacts.

Key-words: Morphometry; Hydrographic basin; Environmental planning.

\section{INTRODUÇÃO}

Os estudos ambientais têm ganhado maior atenção nas últimas décadas devido a intensificação de uma relação homem-natureza de modo cada vez mais predatória. Dentro das ciências geomorfológicas, as pesquisas ambientais considerando o homem como um dos agentes modificadores do relevo também tem se destacado, cumprindo assim uma exigência das pesquisas ambientais atuais com uma abordagem holística dos temas.

Neste âmbito, a bacia hidrográfica tem sido a escala de análise espacial preferencialmente adotada, essencialmente no que concerne aos estudos referentes a gestão e planejamento dos recursos hídricos. Isso se dá pela possibilidade de análise integrada entre os elementos que a constitui (geologia, pedologia, geomorfologia, clima e uso e cobertura vegetal) (SANTOS 2004).

Dessa forma, a Lei Federal 9.433/1997, em seu artigo 1ํㅡㄹ inciso V, ao dispor sobre a Política Nacional de Recursos Hídricos, apresenta a bacia hidrográfica como essencial para o planejamento ambiental, tendo caráter físico-territorial, sendo necessário nos estudos desta unidade de paisagem, uma visão sistêmica, abarcando aspectos socioambientais, políticos e culturais (BRASIL, 1997).

Dentre as ferramentas utilizadas para a o planejamento ambiental em bacias hidrográficas, o uso da morfometria tem se mostrado eficaz no diagnóstico das características hidrológicas, assim como na prevenção de impactos socioambientais oriundos do uso e ocupação da terra de modo inadequado. Nesta perspectiva, Tonello (2005) ressalta a importância dos dados morfométricos na caracterização e interrelação entre formas e processos ocorrentes em bacias hidrográficas.

Os parâmetros morfométricos estão intrínsecos a geometria do relevo, a qual pode ser dimensionada quantitativamente. Tais dados podem influenciar de modo direto as dinâmicas da bacia. Neste âmbito, a morfometria apresenta estreita relação com as características morfológicas, representadas pelas formas de relevo, que, de acordo com Ross (1990) "não ocorre de maneira aleatória e caótica", porém, dentro de um sistema sendo a morfoestrutura o agente principal, todavia, atuando juntamente com os processos exógenos, responsáveis pela esculturação do relevo.

Portanto, ressalta-se a importância do entendimento dos processos naturais inerentes a bacia para a interpretação de suas informações morfométricas que podem contribuir na prevenção de impactos ambientais, principalmente associados a riscos de 
ANÁLISE MORFOMÉTRICA E DO USO DA TERRA DA BACIA HIDROGRÁFICA DO CÓRREGO DA ONÇA, PRESIDENTE PRUDENTE- SP

alagamentos e processos erosivos acelerados, ligados a diferentes formas de uso da terra.

Sendo assim, a presente pesquisa busca analisar as características morfométricas e do uso da terra no córrego da Onça, no município de Presidente Prudente- SP, como ferramenta ao planejamento ambiental. Deste modo, este estudo tem sua contribuição na disponibilidade de dados referentes as características socioambientais da bacia e de sua suscetibilidade a impactos ambientais associados ao uso da terra, sendo um importante material para o planejamento ambiental da área.

\section{Caracterização da área}

A bacia hidrográfica do córrego da Onça está situada no município de Presidente Prudente- SP, entre as coordenadas $22^{\circ} 05^{\prime} 48^{\prime \prime} \mathrm{S} / 51^{\circ} 23^{\prime} 45^{\prime \prime} \mathrm{O}$ (nascente principal) e $21^{\circ} 59^{\prime} 56^{\prime \prime} \mathrm{S} / 51^{\circ} 17^{\prime} 15^{\prime \prime} \mathrm{O}$ (foz), possuindo uma área de $118,144 \mathrm{Km}^{2}$ e perímetro de 55,2 Km (Figura 1). Sua hidrografia se insere na composição de redes de drenagem com importância regional e nacional, sendo elas as bacias hidrográficas dos rios do Peixe e Paraná, respectivamente.

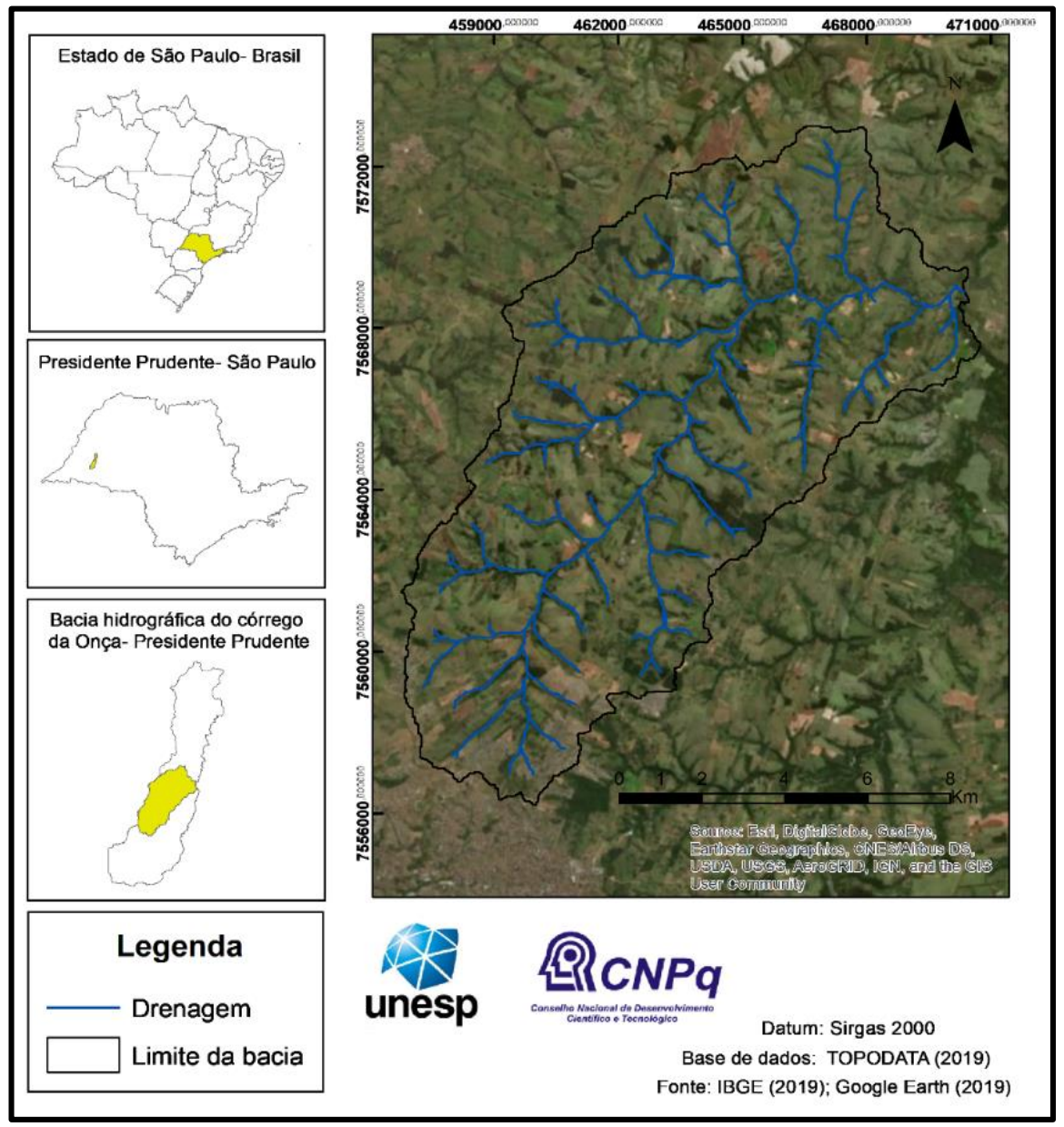

Figura 1- Localização da bacia hidrográfica do córrego da Onça, Presidente Prudente- SP

Elaboração: Os autores (2019) 
ANÁLISE MORFOMÉTRICA E DO USO DA TERRA DA BACIA HIDROGRÁFICA DO CÓRREGO DA ONÇA, PRESIDENTE PRUDENTE- SP

Presidente Prudente se encontra, geomorfologicamente, na morfoestrutura da Bacia Sedimentar do Paraná e na morfoescultura do Planalto Ocidental Paulista, onde há o predomínio de arenitos da Formação Adamantina, correspondente ao grupo Bauru (ROSS e MOROZ, 1996). Embora a altitude neste município varie entre 300 a 600 metros, e a declividade de seu relevo esteja, majoritariamente, entre 10 a $20 \%$, conforme destaca Nunes et al. (2006), a área da bacia hidrográfica do córrego da Onça, apresenta dados hipsométricos entre 325 e 486 metros, enquanto que sua declividade varia entre 0 a $34 \%$ (Figuras 2 e 3 ).

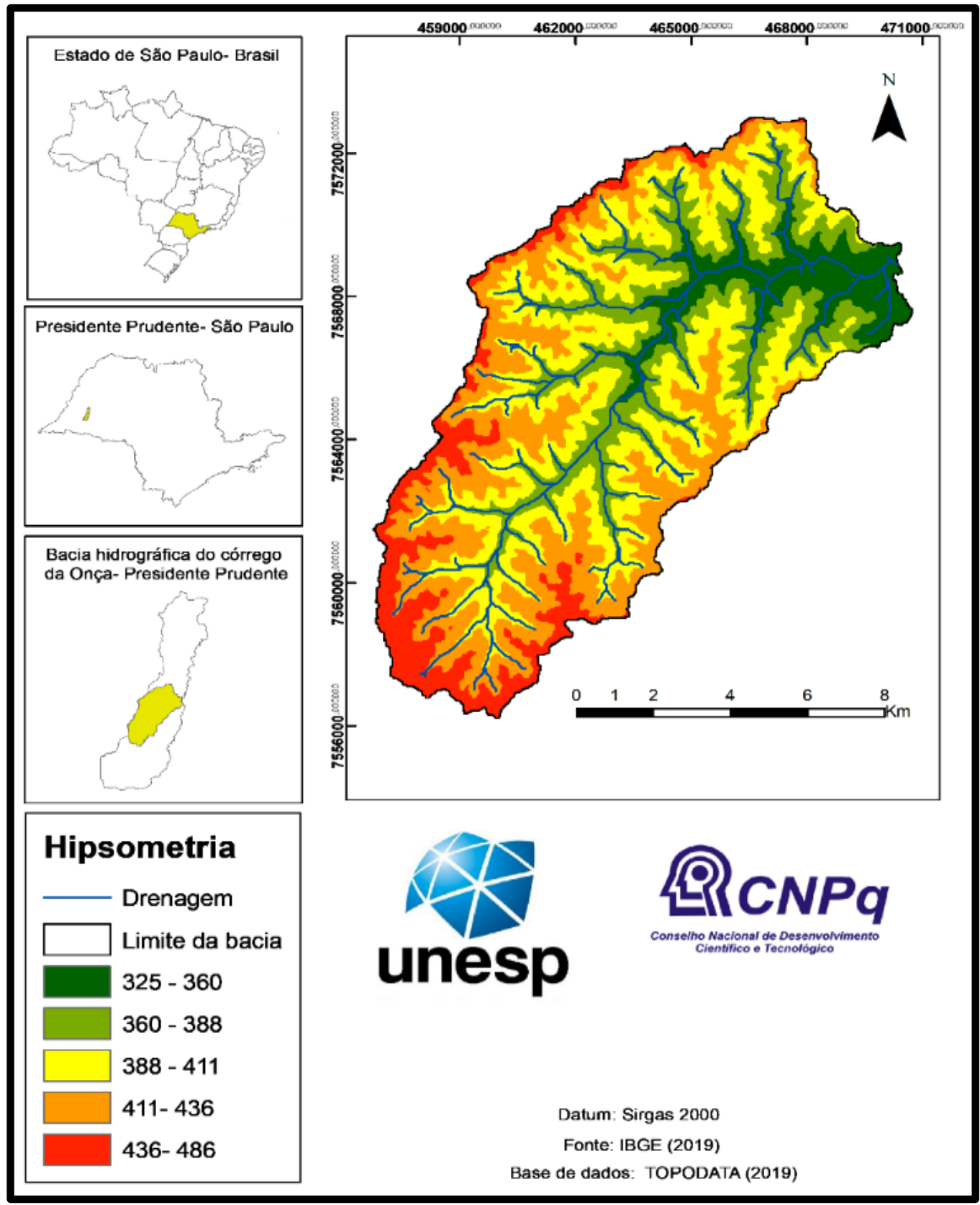

Figura 2- Hipsometria da bacia hidrográfica do córrego da Onça

Elaboração: Os autores (2019). 
No que se refere aos tipos de solos, estudos realizados por Fushimi (2012) sobre as classes de solos no município de Presidente Prudente, apontam que na área da bacia do córrego da Onça há a presença de Solos: Rasos (como associação de Neossolos Rigolíticos), Rasos a Desenvolvidos (associação de Argissolos Vermelhos), Desenvolvidos (associação de Latossolos Vermelhos), e Hidromórficos (associação de Planossolos e Gleissolos).

Os solos rasos são característicos de áreas com maior declividade (> 20\%), situados principalmente em relevos fortemente ondulados, não sendo recomendado para o uso agrícola. Já os solos rasos/desenvolvidos apresentam alta vulnerabilidade à processos erosivos devido sua textura arenosa. Estes estão condicionados a características morfológicas variadas (FUSHIMI, 2012), sendo esta classe pedológica predominante na área de estudo.

Quanto a associação dos solos desenvolvidos, a autora sobrecitada destaca que estão localizados preponderantemente em áreas com gradiente inferior a $5 \%$, possuem grande índice de porosidade, e consequentemente, boa drenagem interna. Salienta-se que esta categoria de solos abarca todos os compartimentos da baca, distribuídos entre a média-baixa vertente. No que atine aos solos hidromórficos, se localizam em áreas aplainadas da baixa vertente, nas planícies de inundação, onde há maior aproximação com o lençol freático. Tais áreas são instáveis naturalmente e, portanto, não designáveis à ocupação (FUSHIMI, 2012). 


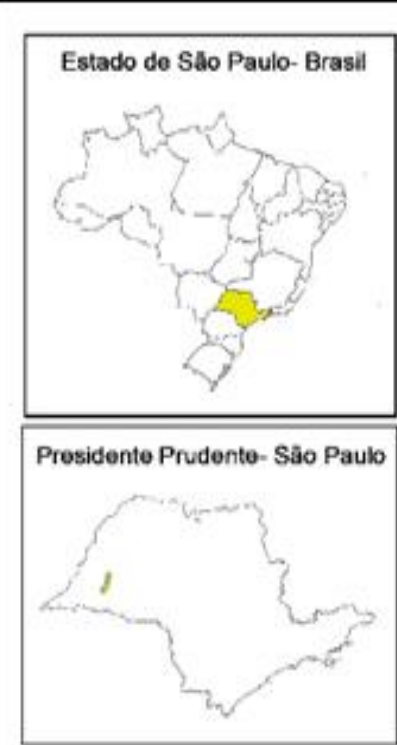

Bacia hidrografica do corrego da Onça- Presidente Prudente
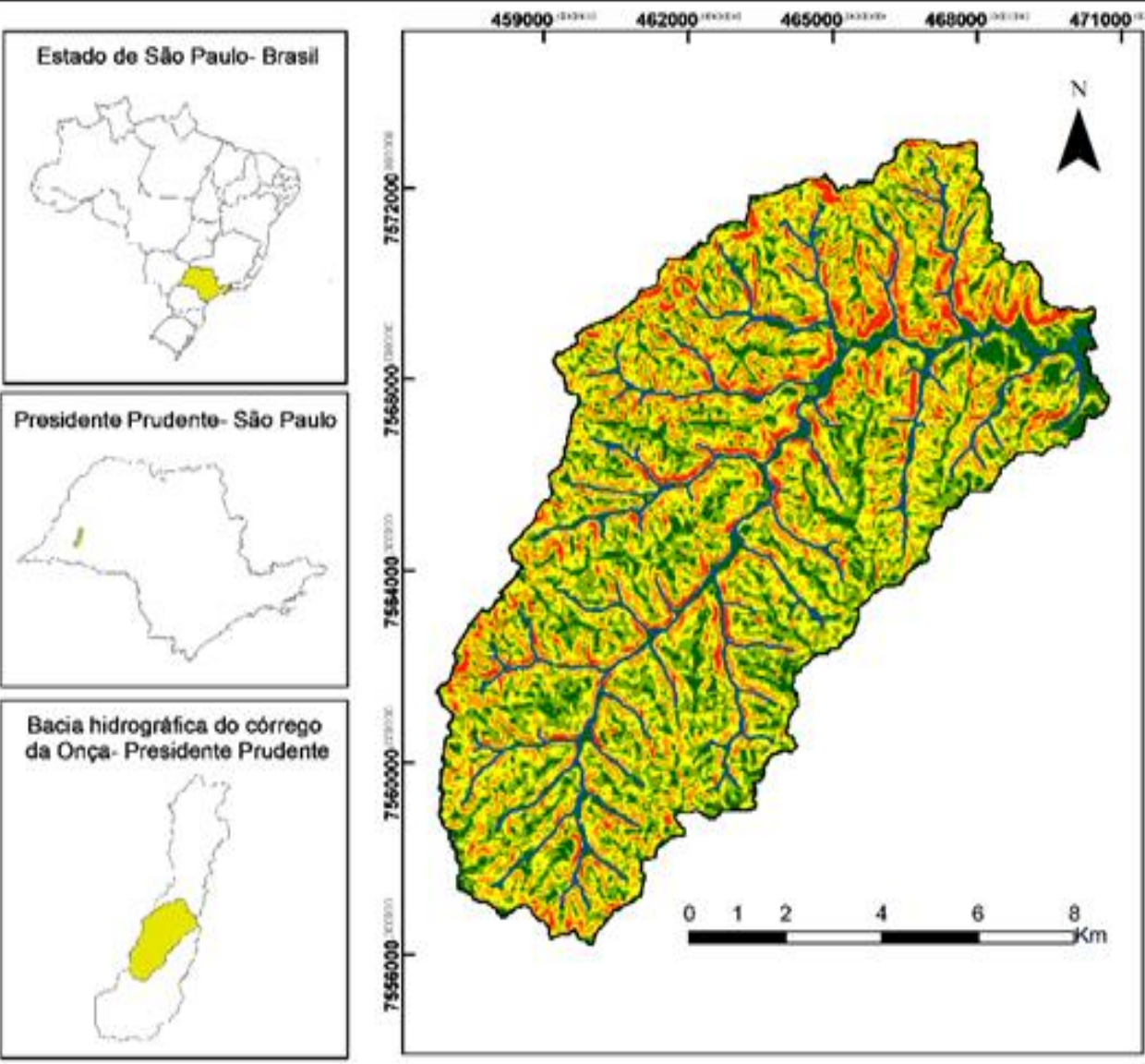

\section{Declividade}
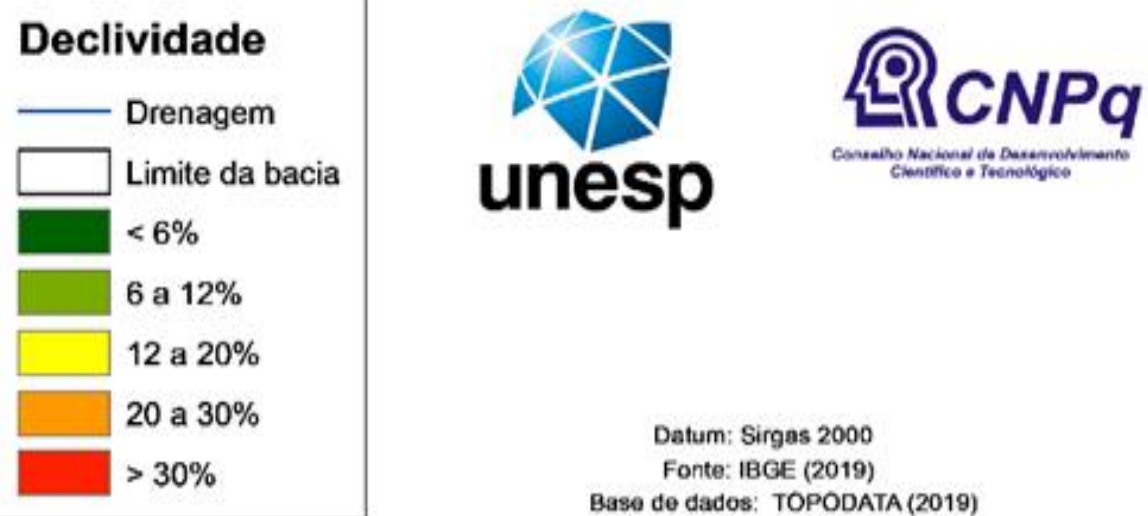

Datum: Sirgas 2000

Fonte: IBGE (2019)

Base de dados: TOPODATA (2019)

Figura 3- Declividade da bacia hidrográfica do córrego da Onça

Elaboração: Os autores (2019).

No que concerne as características climáticas, o município de Presidente Prudente está sob a influência de sistemas polares e tropicais. O primeiro atua durante 0 inverno, repercutindo em um clima frio e seco, enquanto que o segundo está inerente ao período de verão, onde há o predomínio de clima quente e úmido (MONTEIRO, 1973). De acordo com Boin (2000), a média pluviométrica nesta área varia entre 1200 a $1500 \mathrm{~mm}$, enquanto que sua média térmica anual está acima de 22ㅇ․ 


\section{PROCEDIMENTOS METODOLÓGICOS}

A realização deste trabalho se deu em três etapas: 1) elaboração de mapas temáticos com vista tanto a caracterização da área quanto para a aquisição de dados morfométricos; 2) geração do perfil longitudinal do rio principal e 3) o cálculo de dados morfométricos.

A produção cartográfica foi elaborada no software Arc Gis 10.3, sendo a geração dos mapas de hierarquia fluvial, hipsometria e declividade a partir de imagens SRTM, na escala de 1:150.000. Para a hierarquia dos canais, utilizou-se a metodologia de Strahler (1952), sendo este produto o resultado do seguinte processamento: Spatial analyst Tools> Hydrology > Stream Order. O mapa hipsométrico foi gerado a partir das ferramentas Properties> Simbology> Classified. Já no tocante a declividade, o caminho para a geração de seu mapa foi: 3D Analyst Tools> Raster Suface> Slope.

No que atine ao mapa de uso da terra e cobertura vegetal, foi elaborado tendo como base cartográfica, imagens de satélite Landsat 7 e 8, na escala de 1:100.000 e resolução espacial de $15 \mathrm{~m}$ concedido pelo Instituto Nacional de Pesquisas EspaciaisINPE. Utilizou- se a escala temporal de dez anos, sendo avaliadas as mudanças ocorridas entre 2010 e 2020. A classificação dos tipos de uso foi realizada por meio do método de classificação supervisionada, seguindo os seguintes procedimentos: Draw Polygon>Classification > Interactive Supervised Classification.

Os dados quantitativos para a análise morfométrica foram obtidos de imagem SRTM, sendo classificados em linear, areal e hipsométrico, conforme a proposta apresentada por Christofoletti (1980). Dessa forma, as variáveis selecionadas foram: a) lineares: Comprimento total dos canais (Lt), Índice de sinuosidade (Is), Extensão do percurso superficial (Eps), Gradiente dos canais $(\mathrm{Gr})$ e Hierarquia fluvial $(\mathrm{H})$; b) areal: Areal: Área (A), Perímetro (P), Índice de circularidade (Ic), Densidade dos rios (Dr), Densidade de drenagem (Dd), Coeficiente de manutenção $(\mathrm{Cm})$, Índice de compacidade $(\mathrm{Kc}), \mathrm{e}, \mathrm{c})$ hipsométrico: Maior altitude (MA), Altitude na foz (AF), Amplitude altimétrica ( $\mathrm{Hm}$ ) e Índice de rugosidade (Ir).

O Índice de Forma (If) foi concebido por meio do cálculo de figuras geométricas realizado no software Google Earth Pro (2019). Neste mesmo software, também foram extraídas as informações referentes ao perfil longitudinal do rio principal, sendo utilizado o item régua para esta função, disponível em ferramentas> régua> linha, e, posteriormente, mostrar perfil de elevação.

Por conseguinte, a Tabela 1 sintetiza as informações sobre os dados morfométricos utilizados, assim como os cálculos necessários para a aquisição dos resultados. 
ANÁLISE MORFOMÉTRICA E DO USO DA TERRA DA BACIA HIDROGRÁFICA DO CÓRREGO DA ONÇA, PRESIDENTE PRUDENTE- SP

Tabela 1- Parâmetros morfométricos analisados na bacia hidrográfica do Córrego da Onça

\begin{tabular}{|c|c|c|c|}
\hline $\begin{array}{c}\text { Características } \\
\text { físicas }\end{array}$ & $\begin{array}{c}\text { Cálculos } \\
\text { morfométricos }\end{array}$ & $\begin{array}{l}\text { Identificação } \\
\text { das variáveis }\end{array}$ & Categoria $^{b}$ \\
\hline Comprimento total dos canais & Arc Gis 10.3 & - & \multirow{8}{*}{ Linear } \\
\hline $\begin{array}{l}\text { Extensão do percurso } \\
\text { superficial a }^{\text {a }}\end{array}$ & $\mathrm{Eps}=1 / 2 . \mathrm{Dd}$ & Dd- Densidade de drenagem. & \\
\hline \multirow{3}{*}{ Gradiente dos canais $^{\mathbf{b}}$} & \multirow{3}{*}{$\mathrm{Gr}=(\mathrm{H}-\mathrm{h} / \mathrm{L}) \cdot 100$} & $\mathrm{H}$ - Altitude da nascente. & \\
\hline & & h- Altitude da foz. & \\
\hline & & $\begin{array}{l}\text { L- Comprimento do rio } \\
\text { principal. }\end{array}$ & \\
\hline \multirow[t]{2}{*}{ Índice de sinuosidade ${ }^{c}$} & \multirow[t]{2}{*}{ Is $=\mathrm{L} / \mathrm{Lt}$} & $\begin{array}{l}\text { L- Comprimento do rio } \\
\text { principal. }\end{array}$ & \\
\hline & & $\begin{array}{l}\text { Lt- Comprimento do eixo da } \\
\text { bacia. }\end{array}$ & \\
\hline Ordem da bacia $^{d}$ & Arc Gis 10.3 & 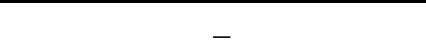 & \\
\hline Área da bacia & Arc Gis 10.3 & \multirow{2}{*}{-} & \multirow{15}{*}{ Areal } \\
\hline Perímetro da bacia & Arc Gis 10.3 & & \\
\hline \multirow[t]{2}{*}{ İndice de circularidade ${ }^{\mathbf{b}}$} & \multirow[t]{2}{*}{$\mathrm{Ic}=12,57^{\star} \mathrm{A} / \mathrm{P} 2$} & A- Área da bacia. & \\
\hline & & P- Perímetro da bacia. & \\
\hline \multirow[t]{2}{*}{ Densidade dos rios ${ }^{\mathbf{b}}$} & \multirow[t]{2}{*}{$\mathrm{Dr}=\mathrm{N} / \mathrm{A}$} & $\mathrm{N}$ - Número de rios. & \\
\hline & & A- Área da bacia. & \\
\hline \multirow[t]{2}{*}{ Densidade de drenagem ${ }^{\mathbf{b}}$} & \multirow[t]{2}{*}{$\mathrm{Dd}=\mathrm{L} / \mathrm{A}$} & $\begin{array}{l}\text { L- Comprimento do rio } \\
\text { principal. }\end{array}$ & \\
\hline & & A- Área da bacia. & \\
\hline Coeficiente de manutenção ${ }^{a}$ & $\mathrm{Cm}=1 / \mathrm{Dd} .1000$ & Dd- Densidade de drenagem. & \\
\hline \multirow[t]{2}{*}{ Índice de compacidade } & \multirow[t]{2}{*}{$K c=P / 2 \cdot \sqrt{3}, 14 . A$} & P- Perímetro da bacia. & \\
\hline & & A- Área da bacia. & \\
\hline \multirow[b]{2}{*}{ Índice de forma ${ }^{\dagger}$} & \multirow[b]{2}{*}{ If $=1-\frac{\text { área } \mathrm{K} \cap \mathrm{L}}{\text { área } \mathrm{KUL}}$} & K- Área da bacia. & \\
\hline & & L- Área da figura geométrica. & \\
\hline Altitude máxima & Arc Gis 10.3 & & \\
\hline Altitude mínima & Arc Gis 10.3 & & \\
\hline \multirow[t]{2}{*}{ Amplitude altimétrica $^{a}$} & \multirow[t]{2}{*}{$\mathrm{Hm}=\mathrm{MA}-\mathrm{AF}$} & MA- Maior altitude. & \multirow{4}{*}{ Hipsométrico } \\
\hline & & AF- Altitude da foz. & \\
\hline \multirow[t]{2}{*}{ Índice de rugosidade $\mathrm{g}$} & \multirow[t]{2}{*}{$\mathrm{Ir}=\mathrm{H} \cdot \mathrm{Dd}$} & H- Amplitude altimétrica. & \\
\hline & & Dd- Densidade de drenagem. & \\
\hline
\end{tabular}

Fonte: a) Schumm (1956); b) Christofoletti (1980); c) Dury (1969); d) Horton; (1945); e) Strahler (1964); f) Lee e Salle (1970); g) Melton (1957). Elaboração: O autor (2019).

Dessa forma, os resultados dos parâmetros morfométricos analisados assim como sua relação com as características socioambientais da área serão apresentados no item a seguir

\section{RESULTADOS E DISCUSSÕES}

Foram calculados dezoito parâmetros morfométricos de modo a analisar as características linear, areal e hipsométricas da bacia, conforme exposto na Tabela 02. 
Tabela 2- Parâmetros morfométricos analisados na bacia hidrográfica do Córrego da Onça

\begin{tabular}{|c|c|c|}
\hline Características físicas & Valores morfométricos & Categoria \\
\hline Comprimento do canal principal & $\mathrm{L}=23 \mathrm{Km}$ & \multirow{6}{*}{ Linear } \\
\hline Comprimento total dos canais & $\mathrm{Lt}=84,3 \mathrm{Km}$ & \\
\hline Extensão do percurso superficial & $\mathrm{Eps}=701 \mathrm{~m}$ & \\
\hline Gradiente dos canais & $\mathrm{Gr}=7 \%$ & \\
\hline Índice de sinuosidade & Is $=1,3$ & \\
\hline Ordem da bacia & Or $=4^{\mathrm{a}}$ ordem & \\
\hline Área da bacia & $A=118,144 \mathrm{Km}^{2}$ & \multirow{12}{*}{ Areal } \\
\hline Perímetro da bacia & $\mathrm{P}=55,2 \mathrm{Km}$ & \\
\hline Índice de circularidade & IC $=0,49$ & \\
\hline Densidade dos rios & $\mathrm{Dr}=0,53$ & \\
\hline Densidade de drenagem & $\mathrm{Dd}=0,71$ & \\
\hline Coeficiente de manutenção & $\mathrm{Cm}=1.402,5 \mathrm{~m}^{2}$ & \\
\hline Índice de compacidade & $\mathrm{Kc}=1,42$ & \\
\hline \multirow{3}{*}{ Índice de forma } & If Circular=0,4 & \\
\hline & If Retangular $=0,06$ & \\
\hline & If Triangular $=0,3$ & \\
\hline Altitude máxima & $\mathrm{NA}=486 \mathrm{~m}$ & \\
\hline Altitude mínima & $\mathrm{NF}=325 \mathrm{~m}$ & \\
\hline Amplitude altimétrica & $\mathrm{Hm}=161 \mathrm{~m}$ & \multirow[t]{2}{*}{ Hipsométrico } \\
\hline Índice de rugosidade & $\mathrm{Ir}=226,7$ & \\
\hline
\end{tabular}

Elaboração: Os autores (2019). Continuação. 
De acordo com Guerra e Cunha (1996) a análise morfométrica em bacias hidrográficas parte da ordenação dos canais fluviais, considerando este procedimento como crucial para a obtenção de outros dados quantitativos. Nesta perspectiva, Strahler (1953) classifica os segmentos fluviais de $1^{\text {a }}$ ordem como aqueles sem tributários, porém o encontro entre dois canais de $1^{\underline{a}}$ ordem resulta em segmentos de $2^{\mathrm{a}}$ ordem, do mesmo modo, da confluência entre dois canais de $2^{\mathrm{a}}$ ordem surgem os de $3^{a}$ ordem, sendo este processo sucessivo.

Utilizando a proposição do autor sobrecitado para a ordenação dos canais fluviais, os resultados demonstraram que a bacia hidrográfica do córrego da Onça possui hierarquia fluvial de $4^{\underline{a}}$ ordem, predominando os canais de $1^{\underline{a}}$ ordem, que se encontram distribuídos entre todos os compartimentos da bacia (Figura 5). Foram quantificados trinta e dois canais de $1^{\underline{a}}$ ordem, quinze de $2^{\mathrm{a}}$ ordem, dez de $3^{\mathrm{a}}$ ordem e seis de $4^{\text {a }}$ ordem, totalizando sessenta e três canais, os quais possuem uma extensão total de $84,3 \mathrm{Km}$.

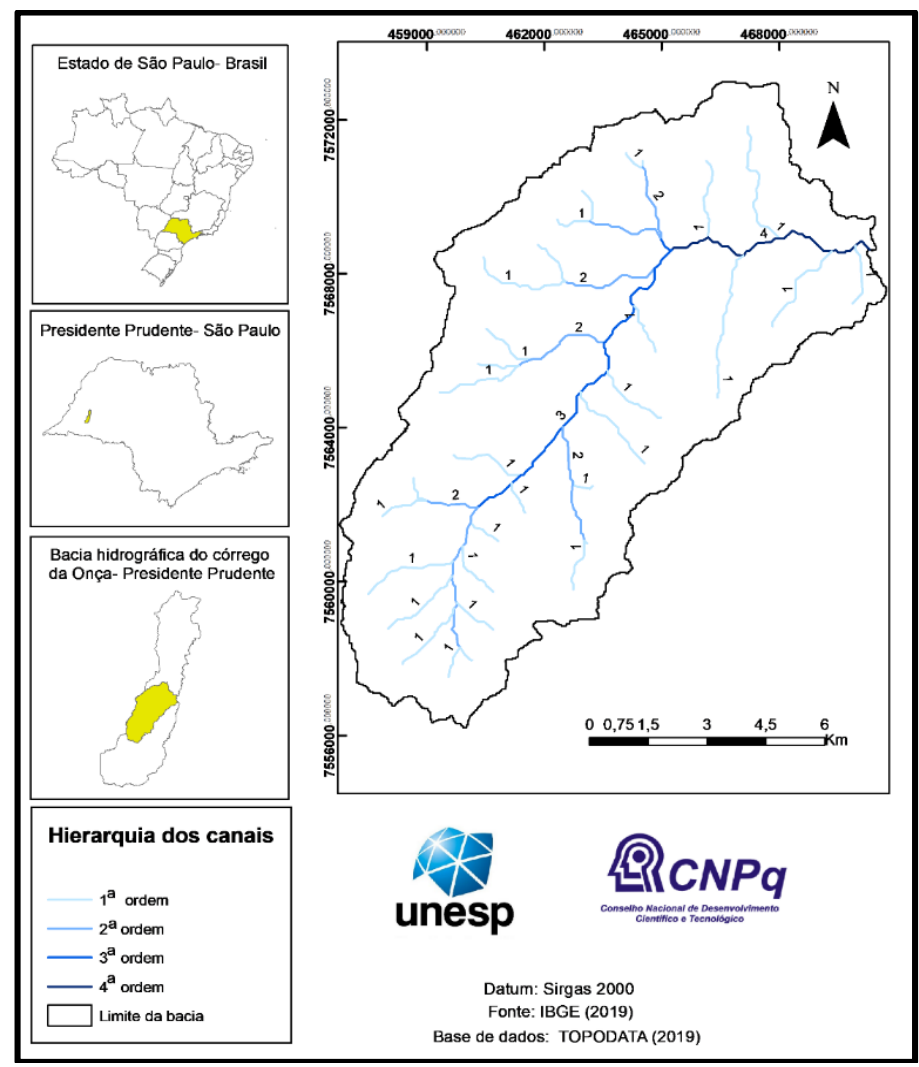

Figura 5- Hierarquia dos fluvial na bacia hidrográfica do córrego da Onça (2019).

Elaboração: Os autores (2019).

No tocante ao gradiente dos canais, observou-se a tendência da própria declividade da bacia, ou seja, a maior parte da área se encontra em níveis de declive entre $<6$ a $20 \%$, classificada segundo o método da Embrapa (1975) como relevo onde predomina morfologias planas e suavemente onduladas. Portanto a média do gradiente dos canais da bacia do córrego da Onça foi de $7 \%$. 
A Extensão do Percurso Superficial foi calculada para a compreensão da distância percorrida pelas águas pluviais entre o interflúvio e os canais. Esta informação mostrase substancial pois pode ser considerada como um indicador à erosão ao longo das vertentes (ROCHA, 1997).

Sousa e Rodrigues (2012) apontam quatro classes para a EPS, a saber: Baixa (> 1000), Mediana (1000-249), Alta (248-142) e Muito alta (<142). O valor de extensão do percurso superficial na bacia do córrego da Onça foi de $701 \mathrm{~m}$, que corresponde a uma taxa mediana, ao aplicar as proposições dos referidos autores. Assim, ao relacionar este índice com geração de processos erosivos, nota- se que na área de estudo há média suscetibilidade, todavia, cabe salientar que a atuação do escoamento superficial sobre solos de caráter arenoso, como os que compõe a bacia, tende a aumentar a fragilidade de remobilização dos solos.

Ao avaliar o Coeficiente de Manutenção, a área mínima para a manutenção de um metro de drenagem foi de 1.402,5 $\mathrm{m}^{2}$. Tal valor pode ser considerado alto, expressando boa área para a manutenção dos canais fluviais (GRANELL-PÉREZ, 2001).

A rede de drenagem da bacia estudada se caracteriza como dendrítica do tipo pinado, que segundo Christofoletti (1980), possui configuração de aspecto arbóreo e os tributários do rio principal se apresentam paralelos formando ângulos agudos. Há nitidamente concentração de tributários provenientes da vertente esquerda do rio principal, assim como a diminuição de canais no baixo curso da bacia quando comparado ao alto-médio curso (Figura 5).

A análise do perfil longitudinal permitiu a obtenção de informações sobre os valores altimétricos do rio principal assim como de sua extensão. Dessa forma o córrego da Onça apresentou 463 m de elevação máxima, localizada na área de sua nascente, e 326 m de elevação mínima, junto a sua foz, tendo, portanto, um desnível altimétrico de 137 m (Figura 6). 


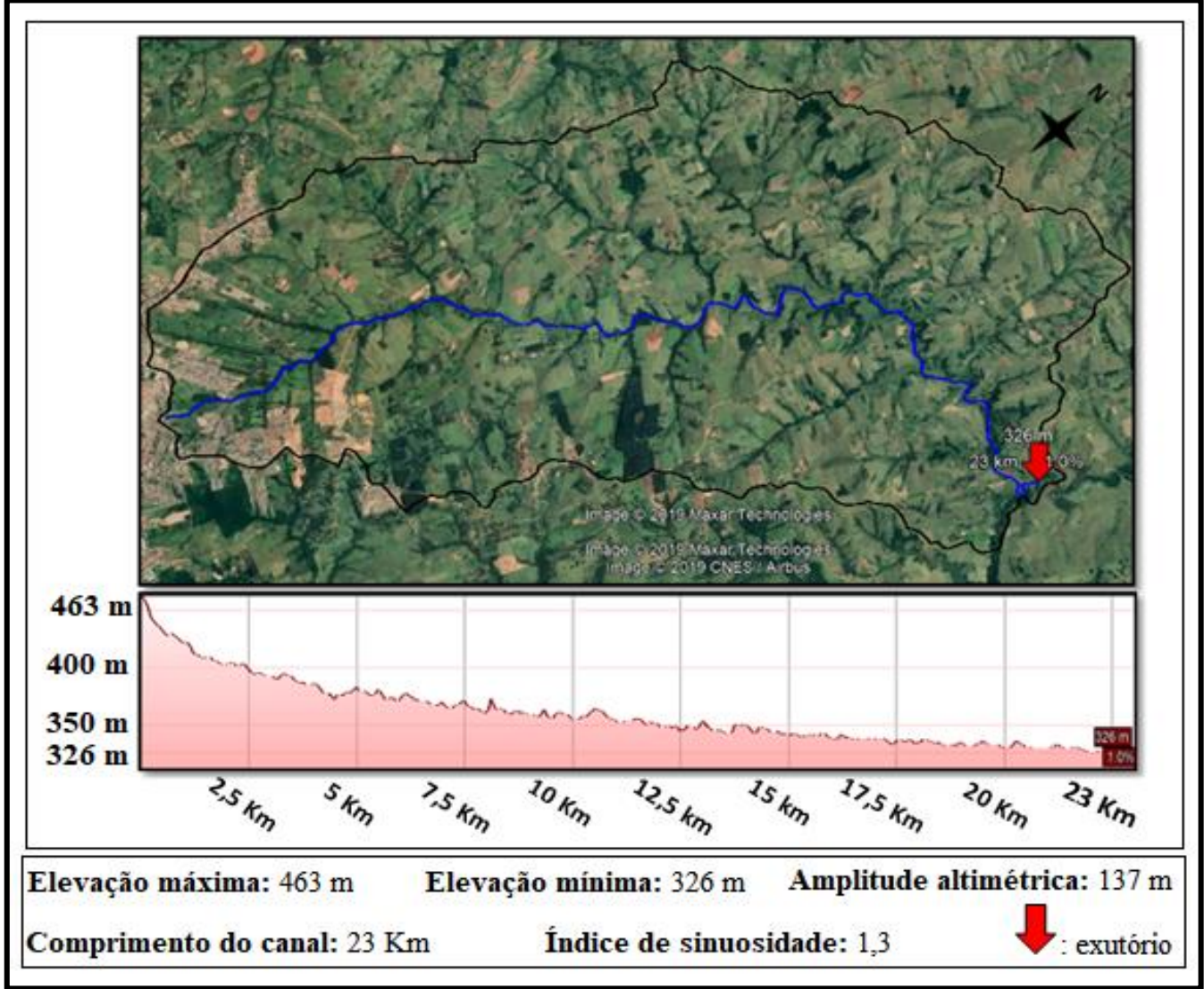

Figura 6- Perfil longitudinal do córrego da Onça. Fonte: Goolge Earth (2019). Elaboração: Os autores (2019).

Segundo Christofoletti (1980) o perfil longitudinal exibe uma característica côncava, com valores de hipsometria e gradiente mais elevados, em áreas de extrema montante do rio, porém, mais suaves em direção ao nível de base. Tais características são expressas pelo autor como perfil de equilíbrio, ou seja, um equilíbrio entre processos erosivos e deposicionais ao longo do curso fluvial. Por conseguinte, rupturas na tendência côncava do perfil longitudinal podem remeter a anomalias ligadas a influências neotectônicas (SUMMERFIELD, 1981).

Ao analisar o perfil longitudinal do córrego da Onça tem-se observado a predominância da forma côncava, denotando a ausência de anomalias ao padrão de drenagem. Seu curso principal apresentou comprimento de $23 \mathrm{Km}$, e ao verificar seu índice de sinuosidade, este se apresentou em 1,3, não sendo classificado como um rio meândrico, pois conforme demonstra Dory (1969 apud Christofoletti, 1980), um rio só recebe a categoria de meandrante quando a relação entre o comprimento do eixo e o comprimento do canal resulta em um índice de sinuosidade a partir de 1,5.

Para analisar o comportamento hidrográfico foi mensurado a densidade dos rios e da drenagem. Sendo o primeiro a capacidade que a bacia tem de gerar novos canais e o 
segundo a relação entre a área da bacia e o comprimento total dos canais (CHRISTOFOLETTI, 1980).

O valor obtido para a densidade dos rios foi de $0,53 \mathrm{~km} / \mathrm{km}^{2}$, enquanto que a densidade de drenagem apresentou índice de $0,71 \mathrm{~km} / \mathrm{km}^{2}$. Esses resultados demonstram índice pobre e regular, respectivamente, considerando a classificação de Villela e Matos (1975). Embora este fator possa estar associado a um conjunto de variáveis (geológica, geomorfológica, clima e vegetação), o elemento preponderante para o índice obtido é o substrado permeável que compõe a região, representado por rochas areníticas da Formação Adamantina possuindo alta capacidade recarga hídrica (GODOY, 1999).

Para avaliar a forma da bacia analisou-se os indicadores Índice de Circularidade, Índice de Forma e o Índice de Compacidade. O resultado do primeiro parâmetro para a área objeto de estudo foi de 0,49. Segundo Miller (1953), este indicador quanto mais próximo de um, maior será a configuração circular da bacia, estando a área de estudo com valor bem abaixo da circularidade, apresentando-se alongada.

Lee e Salle (1970) sugerem o Índice de Forma, onde o tracejado de uma figura geométrica sobrejacente a bacia é utilizado para identificação da semelhança entre elas. O resultado deste método é a classificação da bacia de acordo com os valores obtidos na relação entre as áreas. Para a bacia do córrego da Onça foi calculado o Íf considerando três figuras geométricas: a) círculo; b) retângulo e c) triângulo, as quais demonstraram os seguintes valores: 0,4; 0,3 e 0,06 respectivamente.

Levando em conta que o menor valor do If corresponde a figura geométrica que mais se assemelha a área da bacia- de acordo com os autores supracitados-, a área estudada caracteriza-se por seu aspecto retangular, o que favorece o escoamento, minimizando os riscos de enchentes (Figura 7).

Quanto ao Índice de Compacidade, Villela e Mattos (1975) apontam que os valores superiores a um indicam bacias hidrográficas alongadas, consequentemente índices abaixo deste valor, corresponde a uma bacia circular. Deste modo o quantitativo do Ic foi de 1,42, reiterando a característica alongada da bacia, conforme já verificado nos demais parâmetros relativos a forma. Portanto os resultados para os índices de circularidade, forma e compacidade demonstram que naturalmente a bacia não possui tendência a eventos de enchentes embora esta questão pode ser melhor analisada quando incluem- se outras variáveis para compreender a dinâmica da paisagem como por exemplo o uso da terra. 


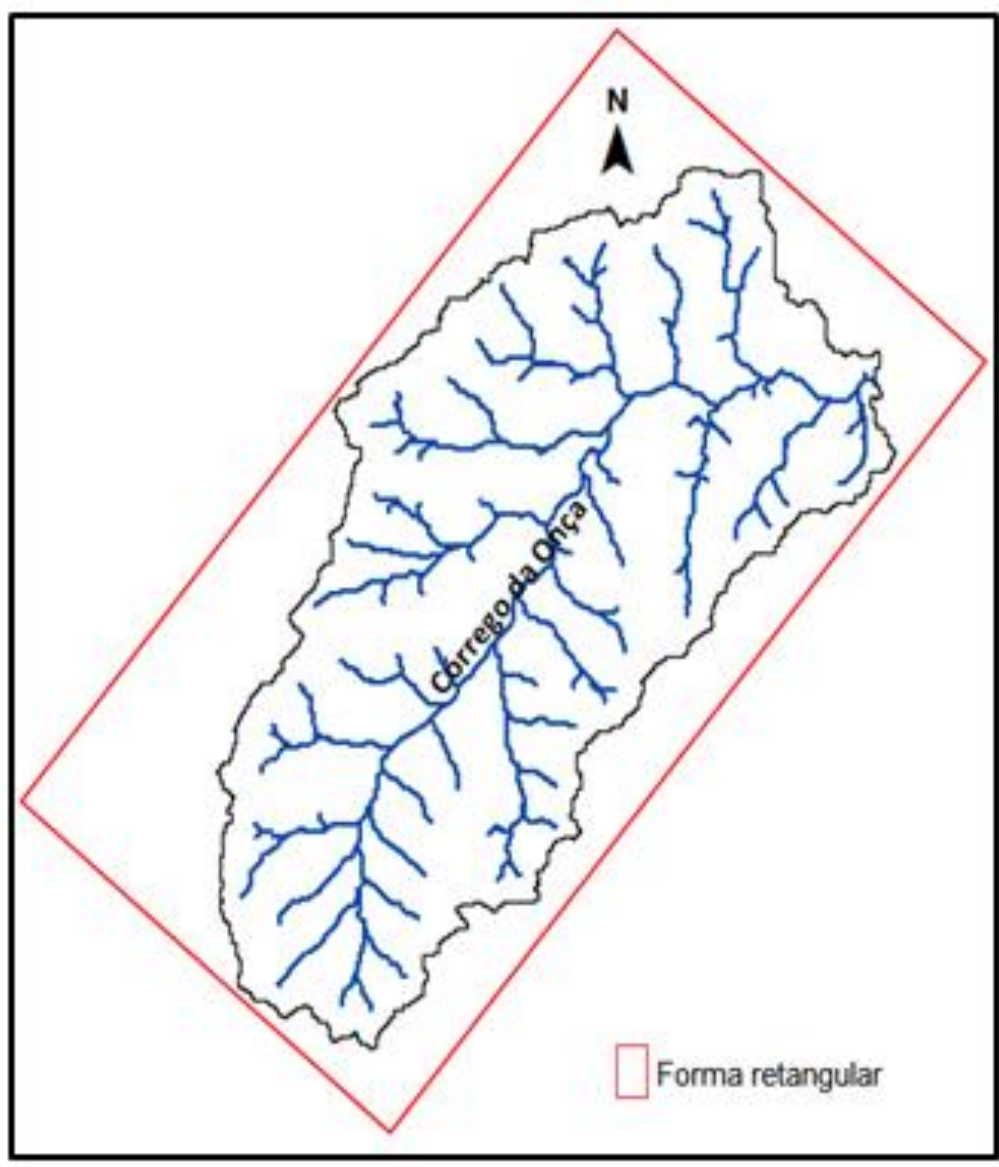

Figura 7- Forma da bacia hidrográfica do córrego da Onça

Fonte: Lee e Salle (1970). Elaboração: Os autores (2019).

Inferiu-se para os valores hipsométricos inerentes a área da bacia, cota máxima de 486 m e mínima de 325, resultando em $161 \mathrm{~m}$ de amplitude altimétrica. Esses dados, assim como os referentes a declividade e a densidade de drenagem, são fundamentais para a análise do Índice de Rugosidade (MELTON, 1957).

$\mathrm{Na}$ relação entre as variáveis que compõe o Ir, quando há o aumento tanto do gradiente das vertentes quanto do comprimento de rampa, tem-se valores deste parâmetro extremamente alto (STRAHLER, 1958). Nesta perspectiva, estudos realizados por Souza e Rodrigues (2012) têm correlacionado o índice de rugosidade com as formas de relevo, obtendo-se quatro classes de rugosidade como se pode observar no Quadro 1. 
Quadro 1- Classes do Índice de Rugosidade em relação a suas formas de relevo

\begin{tabular}{|c|c|l|}
\hline $\begin{array}{c}\text { Classes de } \\
\text { rugosidade }\end{array}$ & Valor & \multicolumn{1}{c|}{ Formas de relevo } \\
\hline Fraca & $0-150$ & Plano com declividade média até 3\% \\
\hline Média & $151-550$ & $\begin{array}{l}\text { Suave ondulado com declividade média entre 3 a } \\
8 \%\end{array}$ \\
\hline Forte & $551-950$ & Ondulado com declividade média entre 9 a 20\% \\
\hline Muito Forte & $>950$ & $\begin{array}{l}\text { Forte ondulado a montanhoso escarpado com } \\
\text { declividade média superior a 20\%. }\end{array}$ \\
\hline
\end{tabular}

Fonte: Souza e Rodrigues (2012). Elaboração: Os autores (2019).

O resultado para a bacia do presente estudo foi de $\mathrm{Ir}=227$ que pode ser classificado como área de rugosidade média, seguindo a metodologia exposta por Souza e Rodrigues (2012). Considerando que este parâmetro possui grande influência nos processos de infiltração e escoamento superficial, as áreas que apresentam forte ou muito forte Ir estão sujeitas a fenômenos erosivos, enquanto que em áreas onde este índice se mostra de médio a fraco, há maior tendência à infiltração, e, consequentemente, a atenuação de eventos erosivos. Todavia, conforme já descrito neste trabalho, a presente área de estudo possui classes de solos naturalmente suscetíveis a erosão e a falta de manejo adequado entre as formas de uso da terra podem condicionar drásticos impactos deletérios ligados a erosão acelerada. Outrossim, o uso e ocupação da terra podem ter efeitos diretos nos processos erosivos e consequentemente repercutir em diversos fatores degradacionais.

\section{Uso da terra}

Identificou- se na bacia do córrego da Onça quatro classes de uso da terra: Área construída, Agropastoril, Cobertura arbórea e Solo exposto. Essas classes foram avaliadas dentro de uma escala temporal de dez anos (2010-2020). Assim, a análise histórica do uso e ocupação da terra demonstraram predomínio da classe de atividades Agropastoris, aumentando sua participação de $53 \%$ da área da bacia em 2010 para $71 \%$ no ano de 2020. No ano de 2010, a participação da área ocupada por Solo Exposto na bacia correspondia a $30 \%$, que se reduziu a $11 \%$ no ano de 2020 , sobretudo em razão da expansão das áreas de atividades agropastoris e também de Áreas construídas (Figuras 8 e 9). 

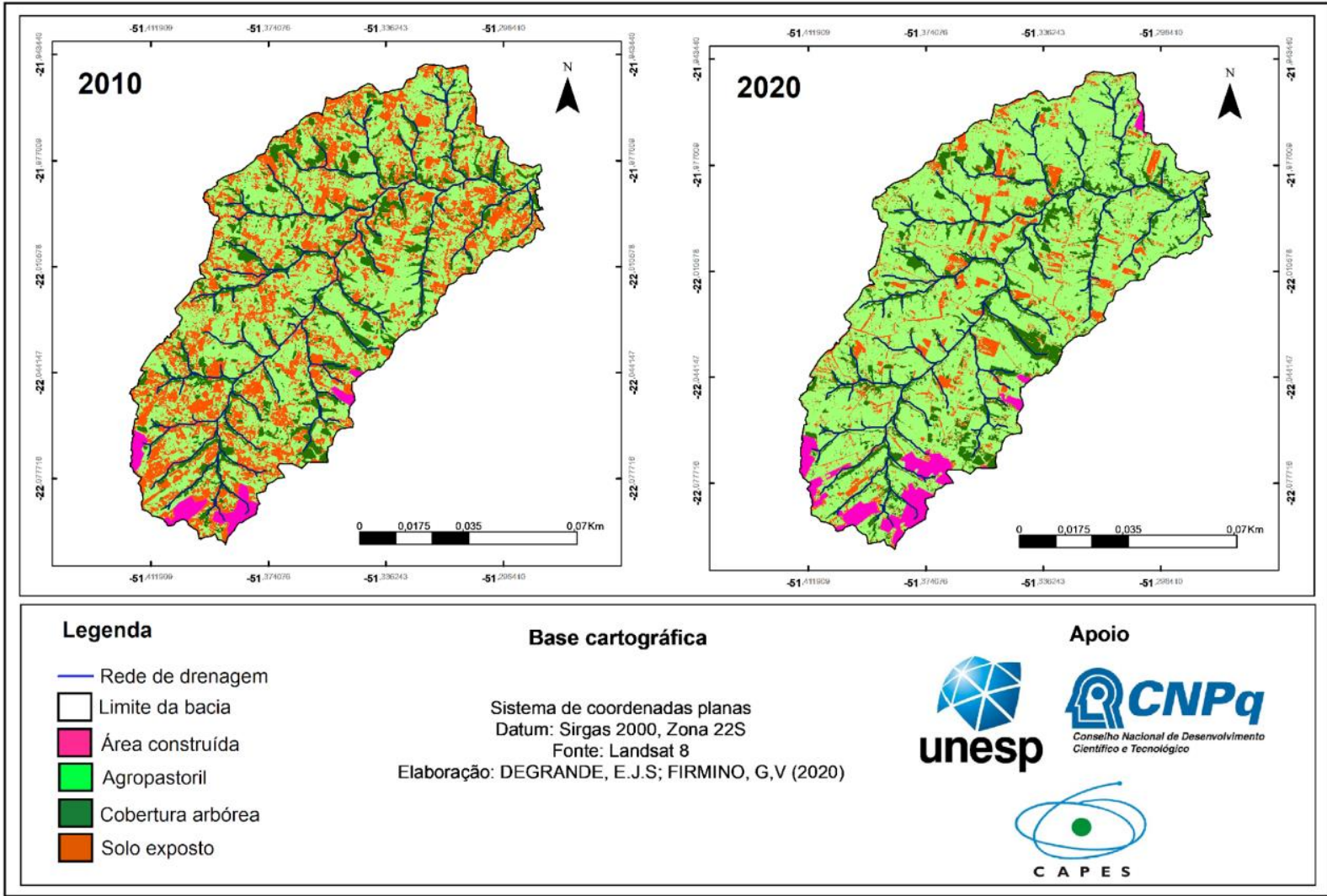

Figura 8 - Mapa histórico de Uso e Ocupação da Terra na bacia hidrográfica do Córrego da Onça nos anos de 2010 e 2020. Elaboração: os autores (2020).

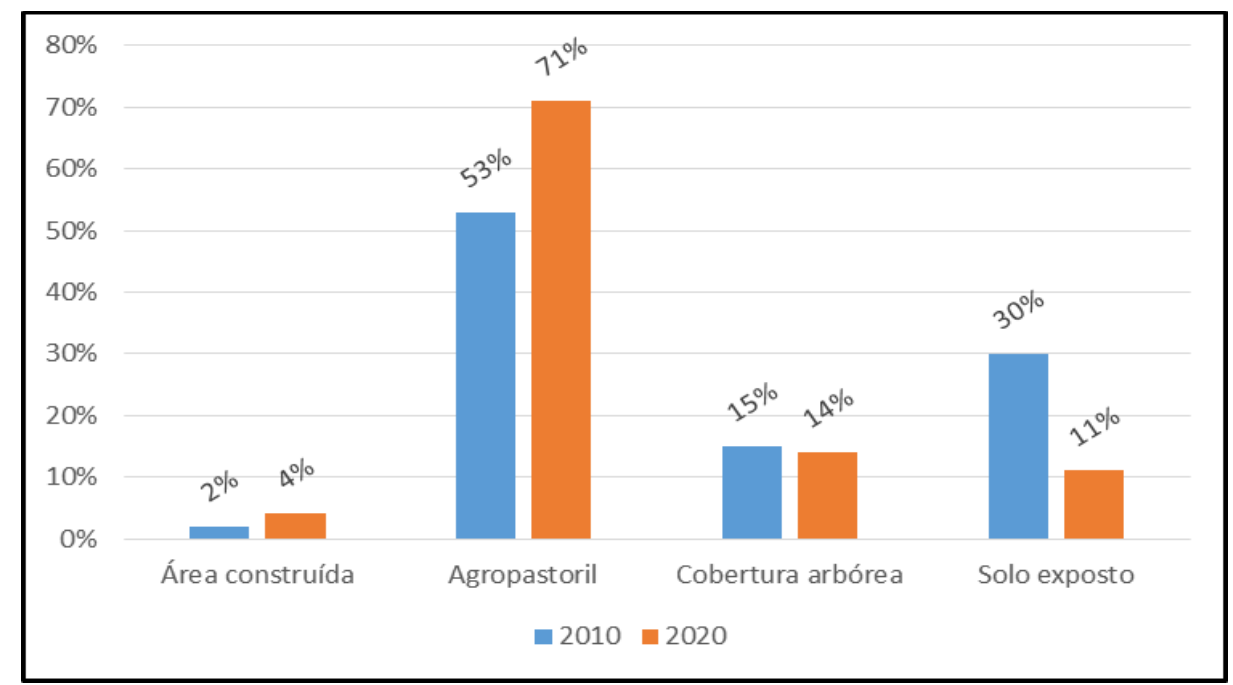

Figura 9 - Gráfico comparativo de Uso e Ocupação da Terra na bacia hidrográfica do Córrego da Onça nos anos de 2010 e 2020. Elaboração: os autores (2020).

O aumento das Áreas Construídas, de $2 \%$ para $4 \%$ de participação na área da bacia, decorre principalmente da expansão urbana que se dá na região do alto curso da bacia, como pode ser observado nas imagens do Google Earth Pro apresentadas na 
ANÁLISE MORFOMÉTRICA E DO USO DA TERRA DA BACIA HIDROGRÁFICA DO CÓRREGO DA ONÇA, PRESIDENTE PRUDENTE- SP

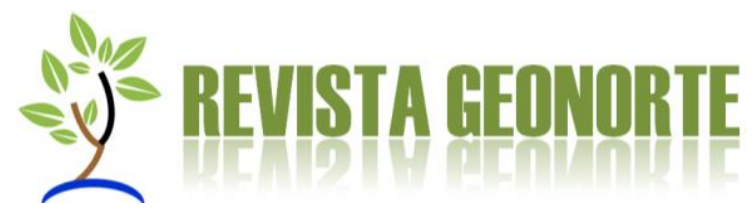

Figura 10. A expansão de atividades agropastoris e áreas construídas também incidiram sobre áreas de Cobertura arbórea, que diminuíram sua participação na área da bacia de $15 \%$ no ano de 2010 para $14 \%$ no ano de 2020 .

A ocupação majoritária e o aumento de atividades agropastoris, a expansão urbana nas cabeceiras e a ocupação de áreas de solo exposto associadas às características pedológicas e à diminuição da cobertura arbórea estão relacionadas ao favorecimento da aceleração de processos erosivos na bacia e ao processo de assoreamento das nascentes.
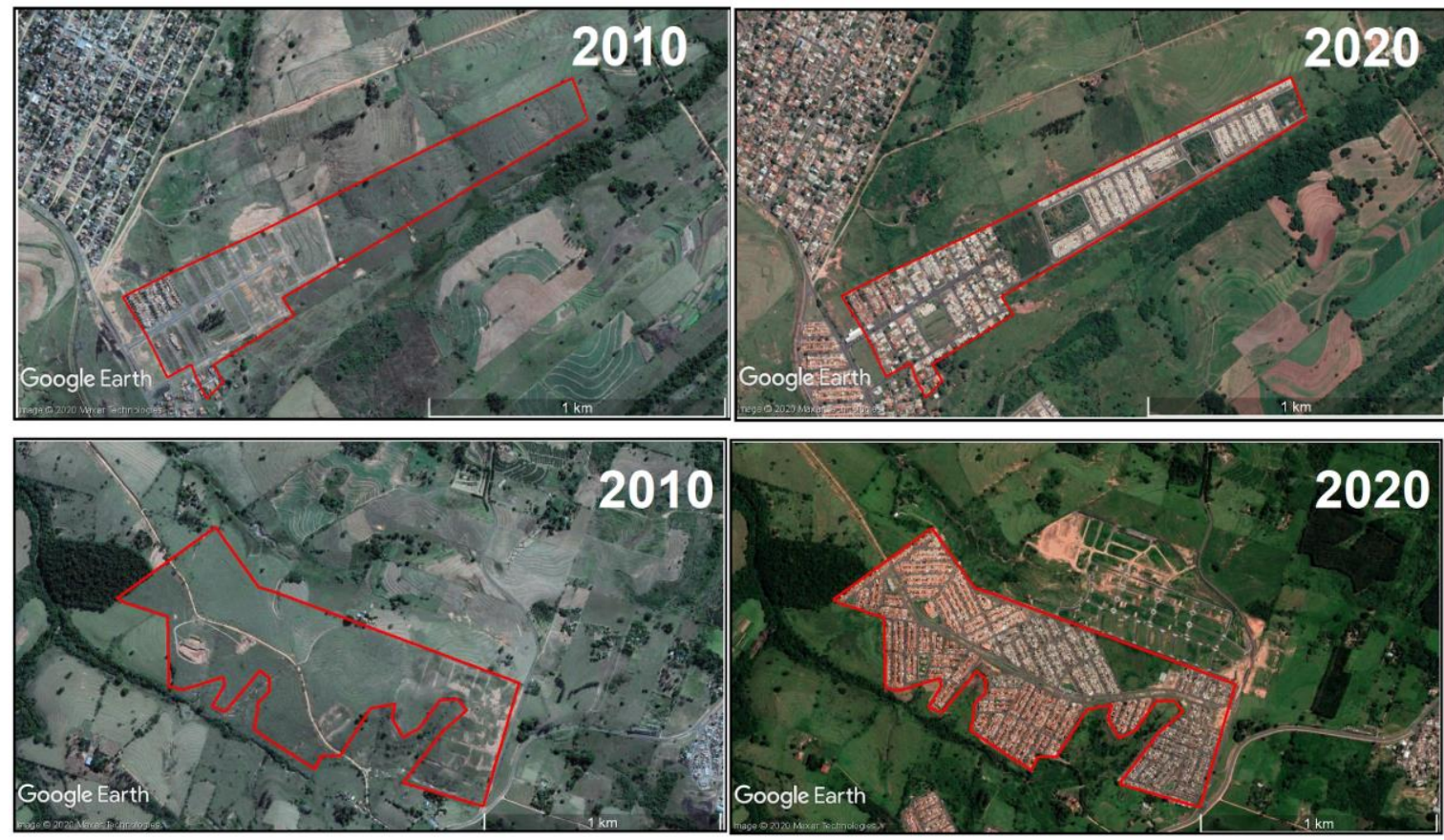

Figura 10 - Comparativo de Imagens Google Earth Pro de 2010 e 2020 demonstrando a expansão urbana da cidade de Presidente Prudente (SP) sobre a região do alto curso da bacia hidrográfica do Córrego da Onça. Fonte??? Elaboração:

\section{CONSIDERAÇÕES FINAIS}

O presente trabalho buscou analisar de modo integrador os elementos que constituem a paisagem da bacia hidrográfica do córrego da Onça. Tal análise, tendo como base a caracterização morfométrica, permitiu inferir que naturalmente a bacia apresenta baixa suscetibilidade a cheias, desconsiderando anomalias climáticas. Esta característica está associada aos baixos índices de densidade dos rios e de drenagem, que tem como principal fator o substrato rochoso constituído de rochas areníticas permeáveis, além da predominância de Latossolos Vermelhos altamente desenvolvidos e com textura arenosa. 
Outrossim, a relação entre os parâmetros Índices de Circularidade, Forma e Compacidade corroboraram para a classificação da forma da bacia que por sua vez foi considerada como retangular, alongada. Portanto, nota-se uma tendência de escoamento, o que auxilia na distribuição das águas pluviais, atenuando os riscos a inundações.

Em contrapartida, ao avaliar o uso da terra na bacia entre 2010 e 2020, nota- se o avanço da ocupação antrópica sobre a área, o que pode gerar novos impactos ambientais, sobretudo o aumento de feições erosivas tendo como consequência o aumento da carga sedimentar aos cursos d'água. Tal fator pode causar o assoreamento dos rios deixando-os suscetíveis a períodos de alagamentos.

O Índice de Rugosidade tem se mostrado médio, sugerindo média vulnerabilidade a processos erosivos, entretanto, cabe ressaltar que os tipos de solos predominantes nesta área são frágeis, devido seu conteúdo arenoso, que os torna facilmente removível. Somado a isto, as formas de uso da terra ao longo dos últimos dez anos têm permitido o avanço das ações antrópicas na bacia possuindo relação direta com o aumento de processos degradacionais.

Portanto, embora as características morfométricas da bacia do córrego da Onça apontam certa estabilidade natural, as formas de uso da terra devem ser avaliadas de modo a conduzi-las adequadamente. Atualmente a bacia se encontra majoritariamente ocupada pelo uso agropecuário, sendo as práticas sustentáveis de manejo do solo a principal forma de evitar processos erosivos acelerados, diante da instabilidade dos tipos de solos.

A área urbana se concentra nas cabeceiras das nascentes principais, demonstrando falta de planejamento ambiental no processo de sua expansão. $O$ aumento de feições erosivas nesta região acarreta no assoreamento das nascentes, impactando todo o processo de drenagem a jusante. Não obstante, diversas manchas classificadas como solo exposto são verdadeiras fontes de sedimentos, transportados para o canal fluvial no período de chuvas. Este processo passa a ser mais intenso em áreas desprotegidas de mata ciliar, que, por sua vez, se apresentam como pequenos fragmentos ao longo do rio principal e seus afluentes.

Desta forma, a metodologia aplicada tem se mostrado eficaz na caracterização hidrogeomorfológica da bacia, sendo um importante instrumento para o planejamento ambiental.

\section{AGRADECIMENTOS}

Ao CNPq e a CAPES pelo apoio financeiro fornecido ao projeto de pesquisa. 


\section{REFERÊNCIAS}

BOIN, M.N. Chuvas e Erosões no Oeste Paulista: Uma Análise Climatológica Aplicada. Tese (Doutorado em Geociências e Meio Ambiente). Universidade Estadual de São Paulo, Rio Claro- SP, 2000. 264f.

BRASIL. Lei n. 9.433, de 8 de janeiro de 1997. Disponível em: <http:// www2.camara.leg.br/legin/fed/lei/1997/lei-9433-8-janeiro-1997-374778-normapl.html>. Acesso em: 10/8/2019.

CHRISTOFOLETTI, A. Análise morfométrica das bacias hidrográficas do Planalto de Poços de Caldas. Tese (Livre Docência em Geociência)- Universidade Estadual de São Paulo, Rio Claro, 1970. $215 f$.

CHRISTOFOLETTI, A. Geomorfologia. São Paulo-SP: Edgard Blücher, 1980, 186p.

DURY, G. H. Tidal stream action and valley meanders. Australian Geographical Studies, v. 7, n. 1, p. 49-56, 1969.

EMBRAPA - Empresa Brasileira de Pesquisa Agropecuária. Centro Nacional de Pesquisa de Solos. Sistema Brasileiro de Classificação de solos. Rio de Janeiro: Embrapa Solos, 1999.

FUSHIMI, M. Vulnerabilidade ambiental aos processos erosivos lineares nas áreas rurais do município de Presidente Prudente- SP. Dissertação (Mestrado em Geografia) - Universidade Estadual Paulista, Presidente Prudente- SP. 2012. $141 \mathrm{f}$.

GODOY, M. C. T. F. Estudo hidrogeológico das zonas não saturada e saturada da formação Adamantina, em Presidente Prudente, Estado de São Paulo. Tese (Doutorado em Recursos Minerais e Hidrogeologia) - Universidade de São Paulo, São Paulo- SP. 1999. 156f

GRANELL-PÉREZ, M. C. Trabalhando Geografia com as cartas topográficas. ljuí: Unijuí. 2001, 128p.

GUERRA, A. J. T; CUNHA, S. B. C. Geomorfologia e Meio Ambiente. Rio de Janeiro: Bertrand Brasil. 1996, 394p.

HORTON, R. E. Erosional development of streams and their drainage basins: Hydrographical approach to quantitative morphology. Geological Society of America Bulletin, v.56, n.2, p.275-370, 1945.

IBGE. Instituto Brasileiro de Geografia e Estatística. Geociências. Disponível em: $<$ https://downloads.ibge.gov.br/downloads_geociencias.htm>. Acesso em: 20/08/2019. 
INPE - Instituto Nacional de Pesquisas Espaciais. Banco de Dados Geomorfométricos do Brasil. Topodata. s.d. Disponível em: < http://www.dsr.inpe.br/topodata/dados.php>. Acesso em: 10/08/2019.

LEE, D.R; SALLE, G.T. Amethod of mensuaring shape. Geographic Review, v 60, n 4 p.555-563, 1970.

MELTON, M. A. Ananalysis of the relations among of climate, surface properties and geomorphology. Technical Report 11. New York: Dept. Geology, Columbia University, 1957. 102p.

MILLER, V.C. A quantitative geomorphic study of drainage basians characteristic in the Clinch Mountain area. Technical Report 3. New York: Dept. Geology, Columbia University, 1953. 30p.

MONTEIRO C.A.F. A dinâmica climática e as chuvas do estado de São Paulo: estudo geográfico sob forma de atlas. São Paulo: USP. 1973, 130p.

NUNES, J. O. R.; FREIRE, R.; PEREZ, I. U. Mapeamento Geomorfológico do perímetro urbano do município de Presidente Prudente- SP. In: VI SIMPÓSIO NACIONAL DE GEOMORFOLOGIA, Goiânia, 2006. Anais... Geomorfologia Tropical e Subtropical: processos, métodos e técnicas, Goiânia: VI SINAGEO, 2006. p. 1-11.

ROCHA, J. S. M. Manual de Projetos Ambientais. Santa Maria: Imprensa Universitária, 1997. 423p.

ROCHA J.S.M; KURTZ; S.M.J.M. Manual de Manejo Integrado de bacias Hidrográficas. Santa Maria: Editora da UFSM, 2001. 282 p.

ROSS, J. L. S. Geomorfologia, Ambiente e Planejamento, São Paulo: Editora Contexto, 1990. 85p.

ROSS, J.L.S; MOROZ, I. C. Mapa geomorfológico do Estado de São Paulo. Revista do Departamento de Geografia (USP), São Paulo, v. 10, p. 41-58, 1996.

SANTOS, R. F. Planejamento ambiental: teoria e prática. São Paulo: Oficina de Textos, 2004. $184 \mathrm{p}$

SOUSA, F.A; RODRIGUES, S.C. Aspectos morfométricos como subsídiomao estudo da condutividade hidráulica e sucetibilidade erosiva dos solos. Mercator, Fortaleza, v.11, n. 25, p. 141-151, 2012.

STRAHLER, A.N., Hypsometric (area-altitude) analysis and erosional topography. Geological Society of America Bulletin, v. 63, p. 1117-1142, 1953. 
STRAHLER, A. N. Quantitative analysis of watershed geomorphology. Transactions of the American Geophysical Union, v.38, n.6, p.913-920, 1957, 1957.

STRALHER, A. Quantitative geomorphology of drainage basins and channel net work. Handbook of Applied Hidrology, p. 4-76, 1964.

SCHUMM, S. A. Sinuosity of alluvial rivers on the great plains. Geological Society of America Bulletin, Denver, Colorado. v. 74 , n. 9, p.1089- 1100, 1963.

SUMMERFIELD, M. A. Global Geomorphology: an introduction of the study of landforms. New York: Routledge, 1991. 537 p.

TONELLO, K. C. Análise Hidroambiental da Bacia Hidrográfica da Cachoeira das Pombas, Guanhães- MG. Dissertação (Mestrado em Ciências Florestais)Universidade Federal de Viçosa, Viçosa- MG. 2005. 69f.

VILLELA, S. M.; MATTOS, A. Hidrologia aplicada. São Paulo: McGraw-Hill, 1975. 